\title{
Configuración urbana de Turín en La bella estate
}

\author{
EDMUNDO GARRRIDO AlARCÓN \\ Universidad Complutense de Madrid \\ egarrido75@gmail.com
}

\section{Resumen}

Desarrollada en una ciudad calco de Turín pero nunca identificada realmente con ella, el espacio urbano se concibe como una ciudad imaginada en torno a la protagonista del relato, Ginia. Esta lectura permite desplegar los aspectos rituales de esta obra de Pavese, en contraste con los aspectos del mito más comúnmente destacados por la crítica. Se plantea la función de los diversos espacios en el proceso narrativo enmarcado en el rito de paso de la adolescencia a la madurez de la protagonista.

Palabras clave: Rito de paso, espacio urbano, Turín, Pavese.

\section{Torino urban configuration in La bella estate}

\begin{abstract}
Developed as a city traced from Turin but never really identified with it, the urban space is conceived as an imagined city around the protagonist of the story, Ginia. This reading of the work allows us to unfurl the ritualistic aspects of this work by Pavese, in contrast to the aspects of myth, more commonly emphasized by the critics. The function of the diverse spaces in the narration is posed in the frame of the rite of passage from adolescence to adulthood of the protagonist.
\end{abstract}

Key words: Rite of passage, urban space, Turin, Pavese.

Garrido Alarcón, Edmundo. 2011. Configuración urbana de Turín en La bella estate. Cuadernos de Filología Italiana, nº extraordinario: págs. 187-195.

El primer problema que presenta el título de este texto es que se basa en un equívoco. La ciudad de Turín no se menciona nunca en el relato La bella estate. Sí se 
menciona en las otras dos novelas incluidas en el volumen publicado originalmente en 1949 bajo este título general y que son Il diavolo sulle colline y Tra donne sole. Es justamente esta diferencia, junto con el espacio de más de ocho años que separa su redacción de las dos siguientes (Carrera 2003: 29), lo que nos ha motivado a analizarla por separado y jugar con la ambigüedad referencial del texto respecto al espacio urbano.

En un primer momento parecía interesante observar cuánto de Turín quedó reflejado en el relato ya que se incluye en una trilogía centrada en esta ciudad pero la ausencia de los elementos que podríamos llamar representativos de su mitología urbana, en el sentido en que lo diría Barthes (1999: 199-257), se puede reseñar brevemente. En el texto de Pavese no hay una sola mención a un elemento geográfico específico de su entorno, ni el río Po ni la Dora Riparia ni los Alpes aparecen mencionados como tales. Tampoco los hitos urbanos singulares como la Mole Antonelliana, el palacio Carignano, la Piazza della Repubblica, la Galleria Subalpina, la Piazza Vittorio Veneto, la ciudad barroca, etc. Ni siquiera la FIAT. Solo se nos indica que los trabajadores son «mecánicos» en vez del término más genérico de «operarios».

Por otra parte, investigando acerca de las representaciones de Turín en la literatura y las artes encontramos la particular visión, también prácticamente desolada, de Frédéric Pajak. Autor multifacético entre ensayista y narrador en un formato híbrido entre novela gráfica y ensayo ilustrado pero, que incluso se podría relacionar con la emblemática barroca, en su obra La inmensa soledad con Friedrich Nietzsche y Cesare Pavese, huérfanos bajo el cielo de Turín, se combinan reflexiones sobre la vida del filósofo y el escritor en la ciudad con experiencias autobiográficas de Pajak. Este libro nos ha ayudado a comprender la concepción espacial de la ciudad en Pavese por cuanto combina la representación de los hitos de la ciudad con otro tipo de representaciones, mucho más subjetivas, del mismo espacio pero en una clave íntima donde el gran edificio deja paso a espacios vacíos y lugares casi insignificantes, en un sentido semiótico, pero que se cargan de sentido por sus habitantes y sus interrelaciones. La ciudad ausente en Pavese, en los aspectos más tradicionales de descripción del espacio marco, aparece, aunque desglosada y distanciada, en las ilustraciones de Pajak. Así mismo, prestaremos especial atención a los pocos espacios descritos en la narrativa pavesiana en contra de los muchos espacios que simplemente significan, en gran medida gracias a su mitología urbana, apenas mencionados.

En un futuro estudio sería interesante contar con los medios para plantear una visión comparada de los espacios de Pavese con los espacios de Pajak recorriendo la ciudad con la prosa y la poesía de Pavese en mente. Esto serviría para plantear un complemento visual y contrapunto narratológico al texto matriz. Las imágenes ayudarían a quienes no conozcan Turín, y a quienes no podremos conocer el Turín de Pavese, a por lo menos ver cómo otro artista elabora su imagen urbana a partir de su lectura de Pavese.

Entonces, nos queda la referencia a Turín como ciudad imaginada en función del relato. Aceptamos que es Turín la ciudad donde suceden los hechos, toda la obra de Pavese refleja esta ciudad, la fábrica, las colinas, etc., pero nos vamos a concentrar 
en la configuración urbana de la ciudad de Ginia, la protagonista. Este punto de vista nos ayudará a plantear una perspectiva paralela, no contradictoria, a la del mito que ha trabajado en especial Furio Jesi respecto a esta obra (1998) y que en general es uno de las grandes fuentes de análisis de la obra pavesiana. La visión propuesta es la del rito, articulada en una configuración de los espacios urbanos como catalizadores del cambio de estado de Ginia.

Como es bien sabido, La bella estate narra el paso de una joven de dieciséis años de una adolescencia casi infantil hacia una problemática madurez. Esta evolución es lo que antropológicamente se conoce como uno de los ritos de paso fundamentales. Sin embargo, uno de los aspectos destacables del relato es mostrarnos cómo estos ritos se han perdido en la sociedad secularizada del siglo XX y los individuos se encuentran sin una comunidad que los mediatice (Segalen 2005: 58-74). Aun estando situada en la contemporaneidad de la Italia de los años cuarenta no hay una sola mención a la Iglesia o una formación religiosa. El espacio de lo sagrado no emerge en ningún punto del relato. Tampoco el espacio de la tradición y la familia como referente temporal de la situación social de Ginia. En este sentido, su familia está constituida por su hermano mayor y parece atrapada en el ciclo industrial. Su hermano, Severino, trabaja en el turno de noche en la fábrica y ella durante el día en un atelier de modas como costurera sin que esto, ni la pérdida de la madre, parezca más que una situación que se ha mantenido así «siempre», en el sentido de que la edad de Ginia, no ha sido el trabajo un símbolo de madurez o independencia. De hecho, Ginia y su hermano aparentan los hábitos de una vieja pareja: «Rosa lo chiamava "tuo marito", per continuare lo scherzo, ma non di rado Ginia si rabbuiava e ribatteva che avere tutte le noie della casa ma non l'uomo, era poco allegro» (Pavese 1998: 4-5; Pavese 2003: 69).

En este sentido la evolución de los hechos muestra claramente la estructura de una novela de formación, o como dice Javier del Prado, una novela de aprendizaje. Aun cuando la «actividad racional, cultural y científica» (Prado 2000: 56) se reduce, esencialmente, a la experiencia vital que conlleva la ampliación del espacio urbano conocido por Ginia y las posibilidades existenciales de cambio que le ofrece en su visión de la realidad, mediatizado por su amiga "adulta", Amelia. A conciencia de que estamos dando el análisis antes de demostrar los fundamentos que nos llevan a él, planteamos esta propuesta con el objeto de dedicar más tiempo a la configuración urbana y su papel catalizador del cambio. Creemos, además, que esta estructura es bastante evidente y que no se opone al análisis mítico planteado por Jesi por medio de los mitos de la fiesta y el sacrificio (Jesi 1998, existe traducción española: Jesi 1972).

Para comenzar a dibujar la configuración urbana de la ciudad en el relato es bueno aclarar que esta obra se concentra en la ciudad. La tan mentada polaridad entre campo y ciudad en la obra de Pavese no está presente aquí. Lo cual no significa que las colinas no estén presentes, pero como un espacio periférico, quizás suburbano, pero en ningún caso campestre. Ir a las colinas en esta obra podría ser como ir a la Casa de campo en Madrid, aunque su nombre insista en el imaginario rural, está o estaba en la frontera entre la ciudad y el campo. No es el espacio mitificado del campo ni «el oscuro mundo de los instintos y las internas ceremonias ini- 
ciáticas» (Carrera 2003: 58). De hecho la única mención relativa al campo en la obra es en referencia a Guido. Cuando Ginia sabe que además de pintor y soldado es de origen campesino le disgusta, « [...] le dispiacque che Guido fosse insomma un contadino. - Da ragazzo andavo scalzo, - le confessò ridendo, e Ginia allora capì il perché delle sue mani forti e di quella voce larga, e non credeva che un contadino potesse fare il pittore. Lo strano era che Guido se ne vantava» (Pavese 1998:70; Pavese 2003:131). Esto más que una señal sobre el desprecio de Ginia respecto a los campesinos es un reflejo de los pobres prejuicios sociales con los cuales Pavese reviste su modo de pensar polarizado, propio de una persona con poca experiencia de la vida. Guido, por el contrario, aunque con una fuerte sensibilidad estética no puede dejar de ser fiel a sus orígenes «Io sto bene soltanto in punta a una collina» (Pavese 1998: 70; Pavese 2003: 131).

La ciudad se configura en espacios concretos que, sin operar como un conjunto, sí tienen un rol en la narración que supera el mero "marco" por cuanto en ellos se cataliza el proceso de maduración de Ginia y se constituyen en espacios de rechazo $o$ deseo que tensionan la estructuración actancial de la intriga. Finalmente, el espacio del deseo, que Ginia quiere habitar, es la buhardilla de Guido, todo lo demás queda afuera y de ahí la quiebra al no poder lograrlo. Sin embargo, podemos hablar de dos tipos de espacios en la ciudad que configurarían las dos categorías básicas con las que vamos a trabajar y que van desarrollando el proceso hasta su punto culminante. En primer lugar, en términos del desarrollo lineal de la historia, los espacios de la adolescencia, y luego, los espacios de la madurez. Al ser el paso de uno a otro un proceso Ginia transita entre ambas series de espacios.

Pavese dibuja rápidamente la vida adolescente de Ginia con su hermano y su amiga Rosa con un grupo de jóvenes mecánicos en torno a la fábrica. Los otros espacios de referencia son la casa, el atelier de modas, la colina, los prados y el río. Justamente es en estos últimos dos espacios donde Pavese sitúa los juegos adolescentes de iniciación sexual. Ginia se siente segregada en su juventud e inexperiencia cuando se queja: «Diceva cosí ma non poteva ripensarci senza umiliazione, perché l'idea che quelle altre senza mai dirlo fossero tutte passate nei prati, mentre a lei, che viveva da sola, la mano di un uomo dava ancora il batticuore, quest'idea le tagliava il fiato» (Pavese 1998: 6-7; Pavese 2003: 71). La cursiva es nuestra; evidentemente «pasar por el prado» es el eufemismo usado para designar la experiencia sexual, marcador del paso de un estado a otro, jugando con la ocultación física pero también con el lenguaje. De este modo, Ginia se siente engañada porque pensaba que las parejas jugaban al escondite entre los matorrales en la ribera del río: "Ginia, scema, immaginando che giocassero a nascondersi, non li aveva cercati e se n'era tornata sulla barca» (Pavese 1998: 8; Pavese 2003: 72). Fuera de este aspecto concreto, por el cual parece que Ginia pasará en breve, como se pasa el rito de paso, sin mayor crisis ya que en la colina se bebe el vino por litros, se canta y se baila, es decir, es un espacio conocido y amigable para Ginia (Pavese 1998: 13; Pavese 2003: 76).

Quizás el aspecto menos explicado, pero más definido de la protagonista es su rechazo por el mundo de la fábrica. Hay algo que la impulsa fuera de su órbita, quizás el vivir sola con su hermano, y la lleva a seguir a Amelia, la "adulta", que tiene 
entre diecinueve y veinte años. Esto se ve claramente cuando piensa en las descarnadas relaciones que se establecen entre las chicas como Rosa y los mecánicos:

- Che cos' hai, Rosa? - diceva qualcuno, mentre si aspettava che cominciasse l'orchestra. - Paura - (e le uscivano gli occhi dalla testa); - ho visto là dietro un vecchio che mi fissa, mi aspetta fuori, ho paura -. L'altro non ci credeva. - Sarà tuo nonno. - Stupido. - Allora balliamo. - No perché ho paura-. Ginia, a metà del giro, sentiva quell'altro gridare: - Sei una maleducata, una strega, vatti a nascondere. Torna in fabbrica! -Allora Rosa rideva e faceva ridere gli altri, ma Ginia, continuando a ballare, pensava che era propio la fabbrica che riduceva così una ragazza. E del resto bastava guardare i meccanici, che anche loro cominciavano la conoscenza facendo questi scherzi (Pavese 1998: 5; Pavese 2003: 69).

Es una ciudad periférica cuyo nexo con la ciudad es la fábrica aunque la acción nunca nos lleve a ella. Es una ciudad clausurada en una dinámica de trabajo en la fábrica y en ocio de la colina. Sus habitantes están atrapados en un círculo de trabajo continuo y de evasión, sin plantearse perspectivas ni tener tiempo, ni posibilidades sociales de vislumbrar una vida diferente, como sí lo hace Ginia.

Curiosamente la calle, especialmente de noche, no es un espacio de aventura, miedo o descubrimiento sino que evoluciona desde el espacio de la intimidad femenina, en términos del lugar donde Ginia y sus amigas pueden hablar ya que la casa es espacio familiar, hacia el espacio de la iniciación sexual lésbica con Amelia, aunque sólo sea a través de un beso (Pavese 1998: 65; Pavese 2003: 126). Esta paradoja de la intimidad en un espacio abierto, la idea de «inmensidad íntima» que desarrolla Bachelard (1975: 220-249), mostrándonos en la categoría de «fuera» lo propio de «dentro», refleja la situación desesperada y marginal del amor de Amelia así como la situación más común de los adolescentes que, por su misma situación, no poseen espacios de intimidad realmente propios y resuelven en la calle, el prado o la colina asuntos tan íntimos como su sexualidad o sus confesiones.

En contraste con la ciudad periférica está la ciudad «central», espacio de la madurez. La ciudad donde se accede a la vida de los artistas aunque no se idealice en ningún momento su rol social. Está configurada principalmente por el café, la buhardilla y algunos espacios «duplicados» como cines y salas de baile que siempre es necesario aclarar que son diferentes a los conocidos por Ginia: «Per questo non andava piú con Rosa alla vecchia sala o nel loro cinema, ma qualche volta usciva sola e correva a un cinema del centro. Poteva farlo lei, se lo faceva Amelia» (Pavese 1998: 17; Pavese 2003: 81). La sala de baile del centro es diferente y afecta emocionalmente a Ginia, es un catalizador colateral del proceso. Su relación ambivalente, de rechazo y deseo, con el espacio escenifica el proceso de maduración:

Amelia non s'era neanche messe le calze, per il caldo; e quando passarono vicino a una sala da ballo, di quelle con l'orchestra sottovoce e i paralumi sui tavolini, Ginia aveva paura di dovercela accompagnare. Non c'era mai stata, e trattenne il fiato. Amelia disse: -non vuoi mica andar qui dentro? (Pavese 1998: 13; Pavese 2003: 76).

Por otro lado, el café, espacio de la madurez en cuanto a lugar público donde las modelos buscan artistas y donde realizan buena parte de su vida los bohemios, sigue 
siendo para Ginia un espacio de la adolescencia, ya que no es reconocida como modelo sino solo como amiga de Amelia, quien lo habita «como si estuviera en su casa»: «L'indomani Ginia andò a cercarla al caffè. Era un caffè nuovo sotto i portici, e Ginia si guardò intorno per trovarci Amelia. Fu Amelia che la chiamò, forte, come fosse in casa sua [...]» (Pavese 1998: 29-30; Pavese 2003: 92). De hecho le resulta un espacio tan ajeno que la voz de la narración introduce una de las pocas descripciones de la novela, en el contexto de una conversación con su amiga que le explica la dinámica laboral del café:

Ginia le vide un bel soprabito grigio e il cappello con la veletta, che la faceva quasi irriconoscibile. Era seduta con le gambe accavallate e il pugno sotto il mento, come posasse. [...]

- Non aspetti nessuno? - chiese Ginia.

- Aspetto sempre, - disse Amelia facendole posto accanto. - È il mio lavoro. Per potersi spogliare davanti a un pittore, bisogna fare la coda.

Amelia aveva sul tavolino un giornale e il pacchetto delle sigarette. Dunque qualcosa guadagnava. [...]

Amelia stava appoggiata allo specchio, come fosse su un sofà. Guardava avanti, nello specchio di fronte, dove Ginia vedeva anche se stessa ma piú bassa. Parevano madre e figlia. - E stai qui sempre? - le chiese. - Vengono qui i pittori?

- Vengono quando han voglia. Oggi non se n'è visti.

Il lampadario era acceso, e molta gente passava davanti alla vetrina. L'ambiente era pieno di fumo, ma così lucido e calmo che i rumori e le voci pareva venissero da lontano. Ginia osservò due ragazze in un angolo che facevano salotto e parlavano col cameriere. - Sono modelle? - disse.

- Non le conosco, - disse Amelia. - Prendi il caffè o l'aperitivo?

Ginia aveva sempre creduto che nei caffè si andasse far coppietta con un uomo, e non si capacitava che Amelia ci passasse i pomeriggi da sola, ma trovò così bello uscendo dall'atelier fare i portici e aver dove andare, che l'indomani ci tornò (Pavese 1998: 30-31; Pavese 2003: 92-93).

Nuevamente el café, como la sala de baile, es un espacio de ambigüedad para la escenificación del rito de paso a la edad adulta de Ginia. La sorpresa ante la soledad de su amiga se desarrolla desde el rechazo a la atracción, pero finalmente solo debe volver a ir al café. Sin embargo, tal hecho no cierra el ciclo. Ginia no solo debe aceptar el espacio como válido, sino que ella misma debe ser aceptada en el ámbito social que marca el café. Incluso después de su intimidad con Guido este no la reconoce como su pareja en el espacio público, sino que la espera a salir del café para llamarla afectuosamente «Ginetta» y abrazarla (Pavese 1998: 86; Pavese 2003: 147). Es un espacio de la madurez al cual la protagonista puede acceder, pero no puede habitar en él; un espacio de tránsito como la calle, pero marcadamente "adulto", en el café se beben copas, no vino como en la colina.

Finalmente, el espacio de la buhardilla resulta totalmente relevante. Recordemos que el título original del relato era La cortina (La tenda, Carrera 2003: 24) que está situada en ella, hecho que sirve para que Pavese introduzca al pintor Barbetta, y poder, de esta manera configurar este espacio separado en dos tiempos. Primero, la buhardilla se revela a la protagonista como el espacio del descubrimiento de un 
mundo diferente al de la fábrica, el mundo del arte; a través del estudio, no buhardilla, donde Ginia es llevada por Amelia, conducida por su curiosidad y deseo de ensanchar los límites de su vida. La buhardilla, según nuestra lectura, es el espacio privilegiado de la catálisis de madurez de Ginia por ser el espacio donde vive la posibilidad de una vida distinta y donde esta, sin embargo, fracasa. Es a través de este desencanto, según comprendemos la visión de Pavese, que Ginia comienza a vislumbrar qué significa ser una mujer adulta. Es la aventura de conocimiento la que la hará regresar a un mundo que permanece igual pero que para ella ha cambiado totalmente debido a su aprendizaje.

Así el personaje de Barbetta y su estudio es mucho más que un simple preludio. La entrada en el espacio desconocido cumple con todas las normas propias del modelo, se entra en un lugar oscuro por un paso difícil, una escalera de caracol, sin embargo detrás de las cortinas hay grandes ventanales que dejan entrar luz y calor. El artista es un hombre afable y cercano que se interesa por ella aunque sea por sus rasgos más infantiles: «si direbbe che il profilo vergine è informe» (Pavese 1998: 20; Pavese 2003: 84) le dice Barbetta. Así el escritor establece una relación directa entre la virginidad, sea metafórica o no, y la forma, la formación del yo, que se alcanza en la madurez. También gracias al contexto de la buhardilla Pavese lanza el tema de la desnudez femenina ante los hombres extraños, hecho que marcará la clave del proceso sexual de Ginia.

Desde la dialéctica de lo alto y lo bajo podemos decir que el único espacio caracterizado como verdaderamente alto respecto a los demás es el de la buhardilla de Guido, al que se accede subiendo a un sexto piso (Pavese 1998: 33; Pavese 2003: 96) y que al subir daba la sensación de que «le scale - non finivano piú - » (Pavese 1998: 38; Pavese 2003: 100). Al estudio de Barbetta se llega por una escalera de caracol, pero nunca se nos especifica su altura, las colinas de la periferia tampoco se caracterizan por permitir una emergencia del yo, solo las del campo, en el imaginario de Guido. De los espacios donde se desarrolla el relato, la buhardilla es el único que puede elevar a Ginia del barro de las calles y de las colinas que desprecia. Este espacio, a pesar de su estado salvaje y sucio, con el decorado sentimental de la lluvia en los cristales, habitado por jóvenes bohemios (Pavese 1998: 36; Pavese 2003: 98) también tiene su propia configuración. Se divide entre el espacio "público" del estudio, propiamente tal, y el espacio "privado" de la cama; este no llega a ser un dormitorio, aunque separado del otro mediante la gran cortina roja ya mencionada (Pavese 1998: 33; Pavese 2003: 96). Asimismo, en una modulación bastante común, la buhardilla cambia dependiendo de sus habitantes. Cuando Guido está, es el espacio deseado de Ginia, en cambio, cuando ella visita el estudio y no lo encuentra, le parece un sitio intolerable: «Guardò indecisa la stanza che con quella luce sembrava propio una miseria, e i cartocci e le cicche buttati per terra [...]» (Pavese 1998: 54-55; Pavese 2003: 116). Sin embargo, esta polaridad desencadena en la protagonista el propósito de apropiarse del espacio mismo. Para que sea el «nido» (recurriendo otra vez a Bachelard (1975: 125)) que se construye y se perfecciona, que se habita. Ginia insiste, casi obsesivamente, mientras está ausente, en limpiarlo e incluso compra una escoba (Pavese 1998: 64-67; Pavese 2003: 125-128), lo que por fin realiza la víspera del regreso de Guido (Pavese 1998: 84; Pavese 2003: 145). Justa- 
mente esta insistencia de Ginia en "domesticar" la buhardilla determinará el contrapeso temático-espacial que marca el momento crucial del relato. Cuando Ginia reconoce, sola y desnuda ante el espejo de su habitación, de regreso en su casa, casi al final del relato, que no tiene más intimidad que esa, y que ha fracasado: «Provò un brivido una volta, come una carezza, spogliandosi per andare a letto, e allora si mise davanti allo specchio, si guardò senza paura e alzò le braccia sul capo, girandosi adagio, col cuore in gola. «Ecco, se adesso entrasse Guido, che cosa direbbe?» si chiedeva, e sapeva benissimo che Guido a lei non ci pensava nemmeno. «Neanche l'addio ci siamo dati», balbettò, e corse a letto per non piangere nuda». (Pavese 1998: 103; Pavese 2003: 162). Este es un pasaje textual que pasa casi desapercibido en la desolación y sequedad de la prosa pavesiana, y que quizás sea su mayor virtud, al apartarse del dramatismo existencial del personaje femenino, para hacer emerger la vacuidad de la existencia madura frente a experiencias que parecen trascendentales a la adolescente.

Así, «Los descensos a los infiernos de las buhardillas» (Jesi 1972: 180) de los que habla Furio Jesi también se pueden leer de una manera más benévola si consideramos que a pesar del desengaño y la soledad, propios de la madurez según Pavese, son los espacios privilegiados del ensanchamiento de la realidad que vive y habita Ginia, así como el comienzo de la búsqueda de una nueva intimidad, por medio del amor, fuera de la casa familiar, un rincón donde hacer suya su propia existencia.

Para terminar, solo queremos destacar que no hay una vinculación entre la oposición fábrica-arte en términos de ascensión desde el rudo mundo obrero al "alto" mundo de la cultura. El único "artista" en el relato, en el sentido moderno del término, es Rodrígues, quien no pinta y prefigura la imagen del "artista conceptual", quizás reflejando, de alguna manera, la figura de Giorgio de Chirico y su representación melancólica de Turín.

Guido es un pintor mucho más sobrio en su acercamiento al medio y modesto en sus aspiraciones estéticas. Quizás cercano al modelo de Giorgio Morandi en su austera representación de la realidad pero sin el paso de este por un proceso de búsqueda que lo llevara a regresar a lo simple, además de la evidente oposición entre la pintura de paisajes y las naturalezas muertas del maestro de Bologna. Dejando a los nombres de referencia de la pintura italiana del momento en que Pavese escribe, aparece la figura de Arturo Tosi (1871 - 1956), pintor de paisajes, colinas, como un modelo bastante cercano al de Guido, en cuanto a temática y estética. Tosi fue un pintor de paisajes que se mantuvo en la tradición de Cèzanne sin dejarse influenciar por el impulso vanguardista. Guido es un pintor, presentado por Pavese, instalado en una concepción similar de la plástica, donde la experimentación es sutil y se expresa en una representación mimética de la realidad. No hay revolución social ni estética en el arte de Guido.

Así, los espacios del arte son tan ingratos para Ginia como los de la fábrica. Guido, artista y soldado, finalmente no es más que un hijo de campesinos. Tampoco hay en esta novela un «neorrealismo» que pretenda analizar realidades sociales concretas, a diferencia de las otras dos obras pavesianas que se publicaron en el mismo volumen (Contarino 1980: 287). Quizás solo podríamos encontrar una lejana relación entre los «pintores» y la adquisición cognitiva de la belleza y la realidad 
en el tiempo de la madurez. Recordemos en este sentido el breve ensayo de Pavese La adolescencia: «Ningún chico, ningún hombre admira un paisaje antes que el arte, la poesía, incluso una simple palabra, le hayan abierto los ojos» (Pavese 1975: 106). Es la idea, ya asentada en la conciencia moderna, de que es la mirada la que construye el paisaje. Quizás, las conversaciones con Guido, la posibilidad de ver colinas con forma de mujer («Guido diceva della colina che voleva fare, e che aveva in mente di trattarla come una donna distesa con le poppe al sole, e darle il fluido e il sapore che sanno le donne» (Pavese 1998: 95; Pavese 2003: 154), podrían abrir la vida de Ginia hacia campos de ensoñación más enriquecedores que la rígida racionalidad del binomio fábrica-colina; estos no se lo permitían. Pero eso es ya ir fuera del texto.

\section{Bibliografía}

BACHELARD, Gaston (1975): La poética del espacio. México, Fondo de Cultura Económica BARTHES, Roland (1999): Mitologías. México, Siglo XXI.

CARrera DíAz, Manuel (2003): «Introducción a C. Pavese», El bello verano. Madrid, Cátedra.

CONTARINO, Rosario (ed.) (1980): L'età presente: dal fascismo agli anni settanta, en C. Muscetta (dir.): La letteratura italiana storia e testi, vol. X, tomo I. Roma, Laterza.

JesI, Furio (1972): «Cesare Pavese: del mito de la fiesta al mito del sacrificio», en F. Jesi, Literatura y mito. Barcelona, Seix Barral, pp. 175-191

JESI, Furio (1998): «Cesare Pavese dal mito della festa al mito del sacrificio», en C. Pavese, La bella estate. Torino, Einaudi, pp. V-XVIII

PAJAK, Frederic (2000): La inmensa soledad con Friedrich Nietzsche y Cesare Pavese, huérfanos bajo el cielo de Turín. Madrid, Síntesis.

PAVESE, Cesare (1975): Literatura y sociedad. Buenos Aires, Siglo XXI.

PAVESE, Cesare (1998): La bella estate. Torino, Einaudi.

PAVESE, Cesare (2003): El bello verano. Madrid, Cátedra.

Prado, Javier del (2000): Análisis e interpretación de la novela. Cinco modos de leer un texto narrativo. Madrid, Síntesis.

SEGALEN, Martine (2005): Ritos y rituales contemporáneos. Madrid, Alianza. 